\title{
San Antonio Report 2005: Diagnostics, Detection, Proteomics, Nanotechnology, Pathology, Operative Techniques
}

\author{
Stefan Paepke Uta Euler Anne K. Baumgärtner Ulrike Schwarz-Boeger Nadia Harbeck \\ Volker R. Jacobs
}

Diagnostische und Operative Senologie, Frauenklinik rechts der Isar, TU München, Germany

\section{Key Words}

Breast cancer: diagnostics, detection, proteomics, nanotechnology, pathology, operative techniques

\section{Summary}

The San Antonio Breast Cancer Symposium (SABCS), the 28th taking place December 8th-11th 2005 again in San Antonio, TX, USA, has become over the years a leading and essential scientific meeting for state-of-theart breast cancer diagnostics and therapy. In the following selected presentations on new developments and latest aspects in nanotechnology, proteomics, pathology, diagnostics and detection as well as in operative techniques including sentinel lymph node biopsy are described, evaluated and summarized.

\section{Nanotechnology - a New Direction for Individualizing Targeted Therapies}

The term 'molecular nanotechnology' has been coined to mean the technology of highly versatile molecular fabrication, molecular manipulation, and molecular-level manufacturing. Molecular nanotechnology has many precedents. Enzymes are natural molecular machines that adsorb to individual reactant molecules from the surrounding solution and, as a result of precisely orienting them with respect to each other in a protected 'nanoenvironment', catalyze reactions in a highly specific manner at very high speeds and under mild reaction conditions [1].

\author{
Schlüsselwörter \\ Mammakarzinom: Diagnostik, Erkennung, Proteomics, \\ Nanotechnologie, Pathologie, operative Techniken
}

\section{Zusammenfassung}

Das 28. San Antonio Breast Cancer Symposium (SABCS), das vom 8.-11. Dezember 2005 wieder in San Antonio, TX, USA, stattfand, ist über die Jahre zum führenden und essentiellen wissenschaftlichen Kongress für Stateof-the-Art-Diagnostik und -Therapie des Mammakarzinoms geworden. Im Folgenden werden ausgewählte Präsentationen zu neuen Entwicklungen und aktuellen Aspekten von Nanotechnologie, Proteomics, Pathologie, Diagnostik und Erkennung sowie operative Techniken einschließlich der Sentinel-Lymphknotenbiopsie beschrieben, bewertet und zusammengefasst.

Yezhelyev and colleagues, Atlanta, [2] presented data for the use of conjugated quantum dots, offering the possibility of detecting and accurately quantifying multiple cellular proteins simultaneously on single tissue specimens, allowing correlation of traditional histopathology and molecular signatures. This is important as the benefit of targeted therapies depends not only on the presence, but also on the quantity of targeted proteins present. Conventional methods do not allow for simultaneous detection and quantification of cellular proteins on single tissue specimens. Fluorescent nanoparticles, such as semiconductor quantum dots exhibit novel optical and electronic properties; can be conjugated to antibodies, and together with wavelength-resolved spectroscopy they can be used to

\begin{tabular}{ll}
\hline KARGER & @ 2006 S. Karger GmbH, Freiburg \\
Fax +49 7614520714 & Accessible online at: \\
$\begin{array}{l}\text { E-mail Information@Karger.de } \\
\text { www.karger.com }\end{array}$ & www.karger.com/brc
\end{tabular}

Dr. Stefan Paepke

Diagnostische und Operative Senologie

Frauenklinik rechts der Isar

Technische Universität München

Ismaninger Str. 22, 81677 München, Germany

E-mail stefan.paepke@lrz.tum.de 
detect and quantify cellular proteins, e.g. the expression of ER, PgR, and HER2/neu.

The results raise new possibilities for nanotechnology applications in molecular pathology and clinical oncology, particularly in linking multiplexed cancer biomarkers with clinical outcome, and facilitating individualized therapy.

\section{Proteomics}

The term proteomics describes the analysis of expression, localization, function, and interaction of proteins expressed by the genome of an organism. In contrast to the rather constant genome of an organism, the proteome (collection of proteins found e.g. in an organism or cell) is constantly changing through biochemical interactions with the genome and its environment. The protein expression in different parts of the body, under different environmental conditions and in different stages of the life cycle can vary considerably [3]. In medicine, proteomics are used to discover new or better drugs and to research new strategies for the treatment of cancer, infections, or special neuropathies. It helps us to unravel biological processes which are relevant in cancer disease $[4,5]$.

On the San Antonio Breast Cancer Symposium (SABCS) Pories et al. [6] from Boston showed a highly significant correlation of urinary biomarkers MMP-9 and ADAM12 with proven risk factors for developing breast cancer when both markers are tested positive. To analyze the urine is advantageous, as it is less invasive, awkward and costly than other screening methods. The London group of Gui et al. could identify new biomarkers for diagnosing breast cancer out of nipple aspirate fluid using SELDI-TOF/MS (Surface enhanced laser/desorption ionisation coupled with time-of-flight mass spectrometry) in combination with multivariate analysis, decision tree artificial neuronal networks and genetic algorithms as artificial intelligence methods [7, 8]. In a pilot study they could demonstrate a clear difference in the protein expression between healthy women and women with breast cancer. This method might become useful in early cancer detection. The measurement of the urokinase-type plasminogen activator (UPA) and inhibitor (PAI-I) in the tumor tissue of node-negative breast cancer patients can spare an adjuvant chemotherapy in almost one third of patients with medium risk as Harbeck et al. [9] could show. This is an example that proteomics can help us to optimize therapy in cancer patients. In his lecture, Margulies [10] demonstrated the involvement of the chemokine IL-8 in the development and growth of osteolytic bone lesions using nude mice. IL- 8 could directly stimulate osteoclasts in vitro and elevated levels in vivo correlated with increased bone metastasis. Treated with a monoclonal antibody directly against IL- 8 the area of osteolytic lesions and tumor burden was significantly lower than in untreated mice. He showed that IL-8 is a potent stimulator of local osteolysis and inhibition of IL- 8 can reduce the bone destruction. In his opinion IL-8 might be an important factor in the pathogenesis of tumor growth and osteolysis and IL-8 antibodies might be useful in the prevention and therapy of bone metastasis. Ongoing research will have to confirm this.

\section{Pathology}

Giuseppe Viale [11], Mailand, presented results from a central review of hormonal receptor- and HER2-status in the BIG 1-98 trial (adjuvant endocrine therapy with letrozol versus tamoxifen in postmenopausal women). A tamoxifen resistance in the subgroup of ER+/PR- and in HER2-positive tumors as mentioned in the ATAC-Trial could not be confirmed. The benefit of letrozol against tamoxifen was similar in all groups.

\section{Diagnostics and Detection}

Under the headline: 'Tomosynthesis: Digital mammography for the 21st century' Elizabeth Rafferty, Massachusetts, presented at a mini symposium the exciting advances in breast imaging possible with tomosynthesis. Using a standard digital mammography platform, tomosynthesis uses multiple lowdose images to reconstruct a 3-dimensional picture of the breast. $20 \%$ of women presenting with breast cancer will have had a negative mammogram because of a so called 'structured noise', anomalous areas created by the overlap of normal breast structures. This structured noise is the result of viewing a 3-dimensional structure in 2 dimensions. Tomosynthesis overcomes this problem by using an x-ray tube that moves in an arc above the breast, taking multiple angled images that allow the radiologists to obtain 'slices' of the breast at regular intervals. The size of the arc and the number of positions can be varied by individual users. Because the angled images use very low radiation doses, the total dose delivered to the patient is equivalent to that used for a single mammographic image. The removal of structured noise significantly improves lesion visualization. Even in cases where mammography is optimally effective, such as in the analysis of fatty breasts, tomosynthesis has been able to identify previously undetected lesions. It can effectively detect very subtle calcifications in previously treated breasts, allowing early and definitive localization of recurrent ductal carcinoma in situ. The ability to differentiate between benign and malignant lesions is significantly improved. Lesions are more accurately localized, and margin analysis is improved [12].

\section{Operative Techniques}

The international trend towards minimally invasive diagnostic and operative procedures including breast conserving or less radical surgery continues over the years. Two American 
groups showed that preoperative surgical biopsies to diagnose breast cancer and intraoperative specimen radiation affect the outcome of breast cancer patients. The German gynecologist familiar with the national S3 Guidelines and the EUSOMA Criteria was surprised that German quality of care seems superior to the American standard.

Oncoplastic surgery often requires special techniques in order to restitute the parenchymal defects of the breast and immediate reconstruction techniques are being used more frequently. The Bayreuth modification of the latissimus dorsi muscle flap shows a new method to fill the defect after tumorectomy or mastectomy avoiding the large scar on the back which is not only cosmetically highly acceptable but also shortens the time of surgery enormously because no change of position of the patient is necessary. This method shows very good results without a higher rate of complications or of local recurrences [13].

A reasonable option for selected patients requiring subcutaneous mastectomy is the method of nipple-areola-sparing surgery with complete resection of the retroareolar ductal system. The complete resection of the retroareolar ductal system guarantees a lower local recurrence rate without a higher rate of discomfort or side effects. Due to the small number of patients this study needs a longer follow-up $[14,15]$.

\section{Sentinel Lymph Node Biopsy}

Due to increasing relevance of evidence of micrometastases and single tumor cells and a high false negative sentinel lymph node rate (9.8-28\%) a more accurate, quicker and easier intraoperative assessment of lymph nodes is of increasing importance. Loussouarn et al. [16] tested the sensitivity of imprint cytology and came to the conclusion that this examination is feasible and effective for diagnosis of macrometastasis, but allows a one-step surgical procedure in only $15 \%$.

A successful novel molecular diagnostic method for rapid evaluation of lymph node metastasis in breast cancer was presented by Matsuura et al. [17]. They developed a new intraoperative molecular diagnostic method, a one step nucleid acid amplification (OSNA) to quantitatively measure cytokeratin 19 mRNA expressions. This assay consists of a sample preparation and rapid gene amplification by RT-LAMP (reversetranscriptase loop-mediated isothermal amplification) - the whole process takes only $30 \mathrm{~min}$. A retrospective analysis of
106 lymph nodes with the OSNA-technique showed a sensitivity of $100 \%$ and a specificity of $97.6 \%$. A prospective analysis of 116 lymph nodes showed a sensitivity of $92.3 \%$ and a specificity of $97.8 \%$. Two false-negative lymph nodes contained micrometastasis.

Although sentinel node biopsy has been accepted as standard treatment for patients with node negative breast cancer, the intraoperative evaluation of sentinel lymph nodes by frozen sections is still debated for its accuracy. The necessity of axillary lymph node dissection in patients with positive nodes was assessed in the NSABP B-32-Trial [18]. Data from 1,355 patients with positive sentinel node biopsy were analyzed for factors possibly predicting the presence of positive nodes. The factors evaluated were tumor characteristics, localization and number of removed nodes, but no subgroup could be identified. Various authors mention the relevance of detection of single cells, so the evidence of these cells could be predictive in $14 \%$ for further positive lymph nodes [19, 20].

Charles Cox [19] from Tampa presented the results from a study testing the impact of micrometastatic carcinoma detected by sentinel lymph node biopsy on survival in invasive breast cancer patients. In 3,047 patients with negative sentinel lymph node biopsy ( $\mathrm{H}$ and $\mathrm{E}$ and immunostained) the slides were analyzed and reclassified. In 132 cases micrometastasis (pN1mi), in 153 cases isolated tumor cells $(\mathrm{pN} 0(\mathrm{i}+))$ and in 2,762 cases no metastasis $\mathrm{pN} 0(\mathrm{i}-$ ) could be found. In $12.9 \%$ of the patients with $\mathrm{pN} 0(\mathrm{i}+)$ further positive lymph nodes were found in the conventional axillary dissection. This concludes that in contrast to current guidelines patients with immunostained evidence of isolated tumor cells ( $\mathrm{pNOi+}$ ) a conventional axillary dissection should be recommended. But it has to be considered that patients with micrometastasis or isolated tumor cells without evidence of further positive lymph nodes show no difference in survival compared to patients with pNO(i-).

Data from sentinel node biopsy after primary systemic chemotherapy are still discussed very controversially. Two Japanese groups came to different conclusions and recommendations; pro: Kinoshita et al. presented an identification rate of $93.5 \%$ and a false negative rate of $11.1 \%(n=3 / 27)$ and contra: Jinno et al. published an identification rate of $83.9 \%$ and a false negative rate of $33.3 \%$ in 122 evaluated patients [21, 22].

All the new data have to be evaluated by the guideline comities in order to give clear recommendations for clinical practice.

\section{References}

1 Ferrari M: Nanotechnology in terms of biomedical applications in cancer and opportunities for funding. 28th San Antonio Breast Cancer Symposium (SABCS), San Antonio, TX, USA, December 8th 2005 .
2 Yezhelyev M, Morris C, Gao X, Marcus A, O'Regan RM: Simultaneous and quantitative detection of multiple biomarkers in human breast cancers using semiconductor multicolor quantum dots. Breast Cancer Res Treat 2005;94(Suppl 1):S48 (abstr 1030)

\footnotetext{
3 http://en.wikipedia.org/wiki/Proteomics accessed on April 13th 2006.

4 Twyman RM: Principles of Proteomics. New York, NY, BIOS Scientific Publishers, 2004.

5 Westermeier R, Naven T: Proteomics in Practice: A Laboratory Manual of Proteome Analysis. Weinheim, Wiley-VCH, 2002.
} 
6 Pories SE, Lamb CC, Roy R, Lotz MM, Zurakowski D, Raza S, Wewer U, Scheib RG, Schumer S, Exarhopoulos A, Isakovich N, Louis GW, Anand A, Lenahan C, Kilroy S, Hirshfield-Bartek J, Borges V, Yee BH, Moses MA: Urinary metalloproteinases: a novel non-invasive methodology for breast cancer risk assessment. Breast Cancer Res Treat 2005;94(Suppl 1):S83 (abstr 2001).

7 Dua RS, Noble JL, Locke I, Coulton GR, Eeles R, Isacke CM, Gui GPH: New biomarkers in the detection of breast cancer in nipple aspirate fluid (NAF), using surface enhanced laser/desorption ionisation coupled with time-of-flight mass spectrometry (SELDI-TOF/ MS) in combination with artificial intelligence methods. Breast Cancer Res Treat 2005;94(Suppl 1):S87 (abstr 2013).

8 Noble JL, Dua RS, Locke I, Coulton GR, Eeles R, Isacke CM, Gui GPH: Variation in protein expression patterns of nipple aspirate fluid comparing women with breast cancer and healthy women using time-of-flight mass spectrometry. Breast Cancer Res Treat 2005;94(Suppl 1):S88 (abstr 2015).

9 Herbst F, Paepke D, Gauger K, Gaskill N, Sweep F, Meisner C, Schmitt M, Jaenicke F, Thomssen C, Harbeck N: Molecular risk estimation and adjuvant chemotherapy in node-negative breast cancer patients - a status report of the prospective clinical trial NNBC 3-Europe. Breast Cancer Res Treat 2005;94(Suppl 1):S254 (abstr 6019).

10 Margulies AG, Akel NS, Perrin D, Carver A, Bendre MS, Gaddy D, Suva LJ: IL-8 is involved in the development and growth of osteolytic bone lesions. Breast Cancer Res Treat 2005;94(Suppl 1):S21 (abstr 42).
11 Viale G, Regan M, Dell'Orto P, Del Curto B, Braye S, Orosz Z, Brown R, Olszewski WP, Knox F, Oehlschlegel C, Thürlimann B: Central review of ER, PgR and HER-2 in BIG 1-98 evaluating letrozole vs. tamoxifen as adjuvant endocrine therapy for postmenopausal women with receptor-positive breast cancer. Breast Cancer Res Treat 2005;94 (Suppl 1):S13-14 (abstr 44).

12 Rafferty EA, Kopans DB, Wu T, Moore RH. Tomosynthesis: A new tool for breast cancer detection. Breast Cancer Res Treat 2005;94(Suppl 1):S2 (abstr 5).

13 Euler U, Tulusan AH, Paepke S, Plattner B, Jacobs VR, Kiechle M: A new latissimus dorsi muscle flap technique in oncoplastic surgery - the Bayreuth modification. Breast Cancer Res Treat 2005;94 (Suppl 1):S113 (abstr 2083).

14 Kumar AS, Wijayanayagam A, Foster RD, Mathes S, Kind G, Wolverton D, Au A, Esserman LJ: Optimizing the total skin-sparing mastectomy. Breast Cancer Res Treat 2005;94(Suppl 1):S36 (abstr 406).

15 Paepke S, Schmidt R, Paepke D, Euler U, SchwarzBoeger U, Plattner B, Niemeyer M, Humbert A, Schmalfeldt B, Kiechle M, Jacobs VR: Early results of nipple-areola-sparing subcutaneous mastectomy (NASSM) with complete resection of the retroareolar ductal system (RDS). Breast Cancer Res Treat 2005;94(Suppl 1):S112 (abstr 2081).

16 Loussouarn D, Dupre PF, Sagan C, Dravet F, Toquet C, Pioud R, Francois T, Curtet C, Classe JM: Intra-operative sentinel lymh node assessment of 193 patients with invasive breast carcinoma: does sentinel lymph node intraoperative examination reduce the complementary axillary lymph node dissection? Breast Cancer Res Treat 2005;94(Suppl 1):S42 (abstr 1011).
17 Matsuura N, Tsujimoto M, Nakabayashi K, Daitho M, Ding J, Sonoda R, Kajita M, Otomo Y: Novel molecular diagnostic method for rapid evaluation of lymph node metastasis in breast cancer. Breas Cancer Res Treat 2005;94(Suppl 1):S39 (abstr 1001).

18 Julian TB, Anderson S, Brown A, Krag D, Harlow S, Bear H, Ashikaga T, Weaver D, Miller B, Jalovec L, Frazier T, Noyes RD, Robidoux A, Scarth H, Mammolito D, McCready D, Mamounas E, Costantino J, Wolmark N: Continued technical results of NSABP B-32: Does a positive sentinel node biopsy require an axillary dissection? Breast Cancer Res Treat 2005;94(Suppl 1):S12 (abstr 20).

19 Cox C, Vrcel V, Riker A, White L, Allred N, Ramos D, Myers M, Dupont E, King J, Cantor A, Diaz N: Significance of sentinel lymph node micrometastasis on survival for patients with invasive breast cancer. Breast Cancer Res Treat 2005;94 (Suppl 1):S12 (abstr 21).

20 Wang YS, Yu JM, Liu YB, Wang L, Zhao T, Li JY: The combination of frozen section and enhanced polymer one-step staining immunohistochemistry for the intraoprative diagnosis of sentinel nodes of breast cancer. Breast Cancer Res Treat 2005;94 (Suppl 1):S39 (abstr 1002).

21 Kinoshita T, Fukutomi T, Akashi-Tanaka S, Terada K, Takasugi M, Shimizu C, Ando M, Katsumata N, Fujiwara Y: Sentinel lymph node biopsy for breast cancer patients with clinically negative axillary lymph nodes after neoadjuvant chemotherapy. Breast Cancer Res Treat 2005;94(Suppl 1):S41 (abstr 1008).

22 Jinno H, Ikeda T, Kitajima M, Fujii H, Mukai M: Analysis of sentinel lymph node biopsy in breas cancer patients after neoadjuvant chemotherapy. Breast Cancer Res Treat 2005;94(Suppl 1):S41 (abstr 1007). 